\title{
ATTITUDES ON CHILDREN VICTIMS OF SEXUAL ABUSE AND THE RELEVANCE OF POVERTY REDUCTION POLICIES IN DEVELOPING COUNTRIES: A TANZANIAN PERSPECTIVE
}

\author{
Seraphina M. Bakta \\ Mzumbe University, Morogoro, Tanzania
}

\begin{abstract}
Children who are sexually abused are likely to encounter discrimination, feel blameworthy, and a lack of support from the very people who should support them. Questions asked of the victim, such as "why were you raped," are the norm, though it is the perpetrator who should be asked why he raped. More importantly, poverty in families is both a cause and an effect of child sexual abuse. This paper employs doctrinal research methodology to examine the attitudes to, and cultural perspectives of, child sexual abuse and the relevance of poverty-reduction policies in addressing child sexual abuse. It is argued that there is a link between cultural ideologies and poverty when it comes to child sexual abuse in Tanzania. There, for example, children are abused on the grounds of superstition and the belief that sexual intercourse by an adult with a child will make the perpetrator rich. Furthermore, because of poverty, families are reluctant to report sexual abuse committed within the confines of the family, especially when the perpetrator is a breadwinner, or when there is "compensation". This paper concludes that, despite the fact that Tanzania has taken various measures to address child sexual abuse, cultural ideologies should be addressed hand in hand with comprehensive policies on poverty reduction when addressing child sexual abuse.
\end{abstract}

Keywords: Attitudes; child victim; poverty; sexual abuse; superstition

\section{Introduction}

In various communities, particularly in Africa, talking publicly about sexual abuse is considered taboo. There is still a negative perception of the victims of sexual abuse, not of the perpetrators. Therefore victims are discriminated against and blamed instead of being supported. Counseling services are hardly available. In a way, victims, including those of sexual abuse, are also segregated in the justice system, particularly in Commonwealth jurisdictions. In Commonwealth countries, the common law legal system only passively recognizes victims as they only appear as witnesses and do not have a say on sentence (Bakta, 2018). Arguably, the perception of a community and justice system in the case of child victims is a double jeopardy. This is mainly because - apart from being victims of abuse - most of those who experience violence are from poor families in which they are just victims of circumstances and yet their participation in the justice system is only passive.

It is important to note that sexual abuse is a violation of child rights and states parties to the Convention on the Rights of the Child (CRC) have taken obligations to protect children from all forms of violence (CRC 1989: art. 19). Again, although there is no consensus, human rights scholars are persuaded that poverty is a violation of human rights (Pogge, 2014). Poverty impacts family lives in general and child well-being in particular. It creates a feeling of powerlessness, vulnerability and lack of confidence, and it deprives one of respect for one's dignity. (Compassion,2019). Thus sexual abuse and poverty should also be looked at from a human rights perspective. 
This is particularly important, considering the relationship between sexual abuse and poverty. For instance, the magnitude of sexual abuse in poor countries particularly those in Asia, sub-Saharan Africa and North America are relatively high (Hillis, 2016). This suggests that poor children disproportionately experience violence, especially sexual violence.

Many studies have been conducted on child sexual abuse, customs and sexual abuse and poverty and sexual abuse. Some of these on child sexual abuse include Koyabashi et al. 1995; Lalor, 2004a \& 2004b; Richer et al.,2004; Murray, et al., 2014; Dobowitz, 2017; and Wangamati et al., 2019; on sexual abuse and poverty: Brooks-Gunn and Duncan, 1997;Bower, 2003; and Banwari 2011; and with regard to customs and child sexual abuse, Kenny and McEcheny, 2000; and Shafe and Hutchinson, 2014. While all these are relevant, this paper seeks to address poverty reduction in relation to customs and tradition, both of which influence attitudes on victims of sexual abuse, as well as poverty as a multidimensional factor in child sexual abuse. It is argued that, since poverty, sexual abuse and cultural practices are related, comprehensive poverty-reduction policies in developing countries may be useful in addressing sexual abuse.

\section{Objectives}

This paper examines how child victim support is affected by customs and tradition, particularly within the context of poverty. The paper then concentrates on the relevance of poverty-reduction policies in protecting children from sexual abuse.

The paper is divided into seven sections. After this introduction and these objectives, section two discusses methodology; section three briefly considers perception about and attitudes towards victims of sexual abuse; section four deliberates poverty and sexual abuse in both a global and Tanzanian perspective; section five identifies some measures, particularly policy and legislative measures, that Tanzania has taken with regard to poverty reduction and child sexual abuse; section six focuses on how a holistic approach to poverty reduction and child protection policies may be integrated in addressing child sexual abuse; and section seven concludes.

\section{Research methodology}

This paper employed a doctrinal method to collect data. Traditionally, a doctrinal method was understood to involve a review and analysis of legal materials (Nkansah \& Chibwanda, 2016). However, a doctrinal method was applied in this work in the form of its recently developed approach, known as an interdisciplinary legal approach. In using this approach the investigation is not restricted to the law as it was traditionally understood but rather the law is analyzed in connection with other disciplines, in this instance, socio-economic issues (Nkansah \& Chibwanda, 2016; Fourie, 2015; Taekema \& Van der Burg, 2015). The method was found appropriate because the paper addresses child sexual abuse as a legal component on the one hand and perception, attitudes and poverty as socio-economic issues on the other. The use of the interdisciplinary approach made the review of legal and non-legal materials that enabled the author to analyze and make sense of the information, and draw conclusions.

\section{Perception and attitudes}

Attitudes to and perceptions of child victims of sexual abuse are largely embedded in culture. In African societies, for example, the dominance of the patriarchal system is one of the reasons why men have an absolute right over women and children. In the case of women, men tend to dominate their economic and social life. In addition, despite the evolution of the rights theory in child rights scholarship, in many societies children are still regarded as properties of their fathers/parents. Thus, it is not surprising that in this twenty-first century we still read of and witness fathers selling their own children (BBC, 2019). 
In many societies in Africa it is still acceptable that girls deserve to be sexually abused if they dress in a way that does not conform to the culture, for instance if they wear miniskirts/dresses (UNICEF, 2016). Arguably, "a society in which children have little status or power, where beatings and emotional abuse of children is condoned,...In this sort of society child sexual abuse is not an aberration, but an inevitable consequence" (Lalor, 2004b, 839). The right of the child to express her or his opinion, among other rights, is to a large extent hindered by tradition and customs - children should not speak when adults are speaking. This happens even within the countries that have ratified the Convention on the Rights of the Child (CRC) (United Nations. Convention on the Rights of the Child) and the African Union's African Charter on the Rights and Welfare of the Child (African Union. African Children's Charter).

Tanzania, like many other African states, has ratified the CRC and the African Children's Charter. It has, therefore, undertaken obligations under these instruments to take legislative, administrative, educational and other measures to protect children from all forms of violence (United Nations. Convention on the Rights of the Child, 1989, art.19; African Children's Charter, 1990, art. 16). The obligations, particularly under the African Children's Charter, also include taking measures to eliminate practices that impede child rights. Article 1 (3) of the African Children's Charter provides that "any custom, tradition, cultural or religious practice that is inconsistent with the rights, duties and obligations contained in the present Charter shall, to the extent of such inconsistency, be discouraged." Importantly, art. 21 places obligations on states parties to take all appropriate measures to eliminate harmful social and cultural practices. The phrase "all appropriate measures" is broad and may include policies, legislation, education and programmes, among others. It may also include policies for poverty reduction.

It is important to note that the language used in art. 21 is somehow soft — "discouraged." This suggests that culture, tradition or customs are rooted in individual beliefs and therefore they have to be addressed gently and they be eliminated gradually. Thus, challenging customs and tradition is in itself a challenge. It is against this backdrop that - more than a decade since the two instruments were adopted states - are still grappling with doing away with customs and traditions that are incompatible with the CRC and the African Children's Charter.

Most of customs and traditional practices are poverty related. For instance, female genital mutilation (FGM) is intended to get girls married so that parents would benefit from the bride price. A girl who does not undergo FGM is regarded as not having complied with traditional requirements and is unlikely to get married in communities that accept FGM. In addition, child sexual abuse and the killing of people with albinism are associated with superstition in the belief that such acts would bring fortune or success (UNICEF, 2016). Arguably, eliminating harmful cultural practices is difficult when these co-exist with poverty. It is, thus, important that poverty is addressed not only as a means of protecting children from sexual abuse but also as a way of changing attitudes on victims that are embedded in culture.

\section{Poverty and child sexual abuse: Global and Tanzanian perspectives}

\section{Poverty}

Poverty is a relative term and there is no agreed definition. It has been defined as a "lack of what is necessary for material well-being - especially food but also housing, land, and other assets" (Bizikova, 2011: 1). It is also defined as "pronounced deprivation in well being" (Haughton \& Khandker, 2009:1). It is a lack of command over resources to enable a person to live above a certain threshold (Haughton \& Khandker, 2009). The United Nations Development Programme (UNDP) outlines lack of nutrition, access to clean water and health services, electricity and sanitation, as well as high child mortality rates are among poverty indicators (UNDP, 2018). Globally, about 650 million people live in extreme poverty (Roser \& Ortiz-Ospina, 2017). In terms of regional distribution, the level of poverty is increasing in sub-Saharan Africa while decreasing in all other regions. It is 
estimated that by 2030, nine out of ten of the world's extreme poor will be living in sub-Saharan Africa (World Bank, 2019 (a)).

Tanzania has been ranked 34 globally in the list of poor countries as two-thirds of its population live below the poverty line (Ventura, 2019). Statistics from the Tanzanian National Bureau of Statistics (NBS) indicate that 74 per cent of children in Tanzania live in multidimensional poverty as they are deprived in three or more dimensions: nutrition; health; protection; education; information; sanitation; water, and housing (National Bureau of Statistics, 2016). According to the NBS, more than a quarter of Tanzanians live below the needs poverty line (National Bureau of Statistics, 2016). According to the World Bank (2013:18), 30.8 per cent of Tanzania's population was living in extreme poverty in 2013. However, the level of poverty declined from 34.4 per cent in 2007 to 26.8 per cent in 2016 (World Bank: 2019 (b)). Despite this decline it can be safe to argue that the magnitude of poverty is high. This suggests that a good number of children are prone to sexual abuse, as shown below.

\section{Sexual abuse}

Sexual abuse in this paper is used interchangeably with sexual violence. It is defined as:

The involvement of a child in sexual activity that he or she does not fully comprehend, is unable to give informed consent to, or for which the child is not developmentally prepared and cannot give consent, or that violates the laws or social taboos of society (World Health Organisation, 2003).

The definition of child sexual activity is broad and may include sexual touching and rape. However, most of cases reported in Tanzanian police stations and other authorities are those involving rape. This is because communities tolerate physical and emotional abuse, but not sexual abuse. Thus, while emotional abuse is highly acceptable and may not be reported, sexual abuse is highly unacceptable and community members are willing to report such occurrences (UNICEF, 2016).

The magnitude of child sexual abuse globally is high (Independent Expert on Violence against Children, 2006; WHO, 2003). For instance in 2002 it was estimated that 150 million girls and 73 million boys were sexually abused (United Nations, 2006), while over half of all children, that is one billion children, aged between two and seventeen years of age experienced violence in 2016 (Hillis, 2016). As shown above, about 50 per cent or more of children who experience violence were from Africa, Asia and North America (Hillis, 2016) while Asia and sub-Saharan Africa also have the highest numbers of people who live in extreme poverty (Roser \& OrtizOspina, 2017). This indicates the relationship between poverty and sexual abuse. It is expected that 87 per cent of the world poorest will be in sub-Saharan Africa in 2030 if the current economic growth trends are not changed (Roser \& Ortiz-Ospina, 2017). The inference here is that the magnitude of child sexual abuse in countries where there is extreme poverty will also escalate.

As it is the case at the global level, the magnitude of sexual abuse in Tanzania is high, in fact, Tanzania, Morocco and South Africa are the leading countries as far as sexual abuse in Africa is concerned (Badoe, 2017). Findings from the 2011 survey and those from recent studies suggest that such rates are not declining. For instance, the National Survey on Violence against Children has shown that one out of three girls are sexually abused before attaining 18 and three out of seven boys experience sexual abuse (in the form of sodomy) before the age of 18 (Tanzania, 2011: 27). In 2016 about 2571 incidences of child abuse were reported in different police stations between January and July 2016 according to the Legal and Human Rights Centre \& Zanzibar Legal Services Centre (LHRC) (Legal and Human Rights Centre \& Zanzibar Legal Services Centre, 2016). This number may still be low because many incidences of child abuse are not reported for various reasons, including a fear of reprisals and out-of-court settlements. In addition, as indicated above, most of the incidences reported are those involving rape or sodomy and it hardly includes touching. 
The LHRC recently released a report indicating that the rate of child abuse in mainland Tanzania is alarming. There were 6378 incidences of sexual violence reported in the first six months of 2018 and about 394 children are raped every month in Tanzania (Legal and Human Rights Centre, 2018,172). Ninety-one per cent of incidences of violence reported in the media are of a sexual nature. The remaining nine per cent includes physical and emotional violence (Legal and Human Rights Centre, 2018:175). It may be possible that, in the main, many incidences are reported and receive media attention because, as indicated above, communities tolerate other forms of abuse but not sexual abuse. For instance, physical violence will become a concern and be reported only when a victim has sustained serious injury (UNICEF, 2016). The Legal and Human Rights Centre report also found that poverty is one of the drivers of violence in addition to the separation of parents/divorce and alcohol and drug abuse.

\section{Poverty as a cause and effect of child sexual abuse}

As it has been shown above, the reasons for child sexual abuse are largely associated with poverty. For instance, rural-urban migration for better job opportunities, domestic trafficking in persons and child labor and sexual intercourse with children in the belief that the perpetrator will become rich are common grounds for child sexual abuse. In essence, these are either causes or effects of poverty. For instance, trafficking in persons and superstition may be regarded as causes because they are committed with the aim of mitigating poverty.

\section{(i) Income poverty}

Around 12 million Tanzanians live below the poverty line (World Bank, 2013). Studies in Tanzania point to the fact that children lack proper care because most of their parents' time is devoted to work (UNICEF, 2016). This is particularly in relation to the low-income families that make up the majority of the population of Tanzania. Such parents work mainly as vendors because of the low rate of employment. In addition, most of the vendors are women because of the relatively low ratio of employment between them and men. In general, parents, particularly women, spend most of the time working so as to provide for their families, while less time is dedicated to their children.

It is important to note that in a patriarchal system prevalent in Tanzanian and other African communities, taking care of children is regarded as a woman's role. In addition, poverty and economic hardship is perceived differently by men and women. For men it is regarded as a situation that lowers their status and self-confidence and, therefore, men are willing to desert their families when they unable to provide for them (Narayan et al., 2000). The situation is different with women, for they are ready to hold on and persevere. Children from poor families, therefore, lack proper care, adequate food, and other basic needs. In some instances, children are forced to engage in prostitution because they are asked to contribute to the household income (UNICEF, 2016; Narayan et al., 2000). Poverty is also among the reasons advanced in connection with school drop out, early marriages and child sexual abuse so as to become rich.

In addition, poverty is also associated with non-reporting sexual abuse cases, particularly where the acts are committed within the family and where a perpetrator is a breadwinner, for if a breadwinner is prosecuted and sentenced the whole family is likely to suffer. In some cases, also, victims are paid a certain amount of money as "compensation", so that they do not report the matter to the police or other authorities (UNCEF, 2016).

\section{ii) Rural/urban migration}

The impact of poverty is more intense in rural areas. It is largely for this reason that people tend to migrate from rural to urban areas for greener pastures, without, in some cases, proper arrangements made beforehand. Families in urban areas tend to invite relatives from rural areas to find employment or business opportunities, even though the former do not have enough space to accommodate the latter. Children are forced to share rooms 
and beds with adult family members and, as a result, they are sexually abused (UNICEF, 2016). Child sexual abuse incidences within the family account for about one-third of all child sexual abuse cases (WHO: 2003). In addition to migration as a means to mitigate poverty, the reason families in urban areas would invite extended family from rural areas is embedded in the African tradition of sharing and caring. This extends to a situation where the family offering assistance has limited resources.

\section{iii)Superstition}

On a different account, parents, especially fathers, abuse their children for reasons of superstition. This may happen when they are promised riches if they have sexual intercourse with their daughters. This kind of belief may be associated with tradition and culture, but they may be better explained as result of illiteracy, something that is generally a companion of poverty. Superstition has commonly been a given as a reason why children are sexually abused and others are killed so that their parents may become rich (The Citizen Tanzania, 2019). Incidences of children being sold by their parents and consequently murdered for rituals are not uncommon in Tanzania (BBC Swahili News, 2019).

\section{iv) Trafficking in persons}

Trafficking in persons is defined as:

The recruitment, transportation, transfer, harbouring or receipt of persons, by means of the threat or use of force or other forms of coercion, of abduction, of fraud, of deception, of the abuse of power or of a position of vulnerability or of the giving or receiving of payments or benefits to achieve the consent of a person having control over another person, for the purpose of exploitation. Exploitation shall include, at a minimum, the exploitation of the prostitution of others or other forms of sexual exploitation, forced labour or services, slavery or practices similar to slavery, servitude or the removal of organs (United Nations. General Assembly. Protocol to Prevent, Suppress and Punish Trafficking in Persons, 2000, art. 3).

This definition is broad enough to capture incidences of children who are recruited from rural areas in Tanzania, particularly from the Singida, Iringa and Dodoma regions, to engage in domestic works in urban areas Kamazima, Ezekiel \& Kazaura, 2016). Children are also trafficked for exploitation in commercial sex, particularly along the Tanzania-Kenya borders (Kamazima et al., 2016). It has been noted that internal trafficking is more prevalent than transnational trafficking and the former is facilitated by victims' families, relatives and intermediaries (United States. Department of State, 2018). Poor children, particularly from the rural areas, remain most vulnerable to trafficking. The United States Department of State has observed that

Girls are exploited in domestic servitude throughout the country and in sex trafficking particularly in tourist hubs and along the border with Kenya. Traffickers target young girls from rural and impoverished villages, pay their parents a small fee, and then exploit the girls in sex trafficking to businessmen who believe a myth that having intercourse with a "virgin" will allow their business to prosper (United States. Department of State, 2018).

Further, children are trafficked so as to work as street vendors. Most of them are forced to drop out from schools, and they engage in such activities to either support families or because families do not have enough money to support the children's education. Although the Tanzanian Government has abolished school fees in primary schools and banned other contributions, families are required to provide for their children's transport to and from school, school uniforms and study materials. It is still difficult for poor families to buy school uniforms and study materials. It has also been a common practice for parents to allow their daughters to drop out of school and get married so that parents will get a bride price. It can, therefore, be argued that trafficking in person and child labour is, to a great extent, associated with poverty. 


\section{Policy and other measures to address violence and poverty}

Tanzania has taken various legislative, administrative and programmatic measures to address poverty in general and the effects of poverty, such as trafficking in persons, in particular. These measures are consistent with her international obligations as shown in 2.0 above. It has enacted the Law of the Child Act which complements penal legislation, as some provisions have been enacted with a view to protecting children and women from abuse, for instance Sexual Offences Special Provisions Act, of 1998. It also has in place some polices, including the National Costed Plan of Action I and II for the Most Vulnerable Children 2007-2010 (NCPAMVC-I) and the National Costed Plan of Action for the Most Vulnerable Children 2013-2017(NCPA-MVC II) respectively. The National Costed Plan of Action I and II for the Most Vulnerable Children 2007-2010 (:8) defines a vulnerable child as one who is living in high-risk circumstances whose prospects for continued growth and development are seriously impaired.

One of the thematic areas of focus in NCPA I is protecting vulnerable children from abuse (NCPA I, 20072010: 3). Importantly it establishes Districts and Village Most Vulnerable Children Committees (MVCC) from such very low governance levels (NCPAI, 2007-2010: 7). Further, the government recognises the need to address poverty as indicated in the National Strategy for Growth and Poverty Reduction (NSGPR, 2010-2015). Although the term of this Strategy has elapsed, Tanzania is being guided by Sustainable Development Goals (SDGs). Importantly, the objectives of the Strategy are linked with the existing Development Vision 2025. For instance, according to this Development Vision Tanzania is committed to implementing Sustainable Development Goal, poverty reduction, among other commitments. Further, the Strategy seeks to protect and to empower the most vulnerable groups in the communities (Tanzania. Development Vision, 2025:18).

In line with the Poverty Reduction Strategy as well as the Development Vision mentioned above, Tanzania has also introduced various programmes to mitigate poverty. These include the Tanzania Social Action Fund (TASAF) which was initiated in 2000 to strengthen social security delivery, especially to vulnerable populations. The Fund is being implemented in phases, whereby phase one (2000-2005) focused on key issues that were identified in the first Poverty Reduction Strategy Paper (PRSP-I), including social service delivery; Phase two (2005 -2013) focused on millennium development goals and the National Strategy for Poverty Reduction (NSPR); and in phase three, approved in 2013, the government approved the implementation of the Productive Social Safety Net (PSSN) programme, a nation-wide conditional cash transfer programme that targets the extremely poor population. There are varying opinions as to the extent to which the programme has achieved its objective. While some beneficiaries applaud it (Yussuph, 2016), others are yet to appreciate its impact (Kimati, 2017).

Tanzania has a number of laws relevant to the protection of children from sexual abuse. These include the Penal Code (Chapter 16 of the Laws of Tanzania) which prescribes offences and sentences, including the offences of rape and indecent assault. The Act, particularly part XV that deals with offences against morality, was amended in 1998 by the Sexual Offences Special Provisions Act. Such amendments included widening the scope of sexual abuse to include sexually oriented acts and words done or said to any person for gratification or any illegal purpose. Further, when a victim of rape is a girl under 18 years the consent of the victim is immaterial. The Act prescribes a sentence of life imprisonment if the victim is a girl aged 10 years or below. Although the Act makes reference to a girl, it may be argued that the inference to the intention of the Parliament suggests that the provision was meant to apply to children and it is not restricted to girls.

Child protection is also taken care of under the Law of the Child Act, 21 of 2009. Section 83 of the Act prohibits sexual exploitation and it places obligations on parents and local government authorities to protect children under ss 9, 94 and 95. Further, child protection, particularly with regard to trafficking in persons, is addressed under the Anti-Trafficking in Persons Act, 6 of 2008. The Act classifies trafficking of a child as severe trafficking punishable with a fine of not less that five million shillings or an imprisonment term of not less than 
ten years or both (Anti-Trafficking in Persons Act, 6 of 2008). However, measures that are being taken to eliminate trafficking are inadequate and fall short of the international standards threshold (United States of America Department of State, 2018).

, Tanzania has introduced police gender desks in every police station to enhance intervention mechanisms. This is a separate unit that comprises a police officer or police officers who are not in police uniforms, a lawyer and a social welfare officer. It is intended to enable victims approach such an office with confidence. Although the desk also deal with gender-based violence, the existence of such a desk has been useful in the intervention of child abuse cases (UNICEF, 2016).

\section{Integrated approach}

Despite these measures, incidences of child sexual abuse are still high. As shown above, such incidences are linked to poverty and cultural practices. These include superstition and the belief that a man may become wealthy if he has sexual intercourse with his daughter or a virgin girl. Other incidences of child abuse include child prostitution and trafficking in persons. As shown above, parents condone many incidences of child trafficking and prostitution either directly or indirectly so as to get money out of it. For instance, parents ask children to contribute to the household knowing that that they do not have a source of income. In other instances, parents allow girl children to drop out of school so that they get married and parents get the bride price. All these are associated with poverty. While measures that the government has taken to address poverty are commendable, much more needs to be done.

It is important that the drivers of child sexual abuse - which in most cases relate to poverty - are identified and documented. For instance, it has been established that lack of education/ignorance and superstition - among the reasons for child sexual abuse - are closely associated with poverty. Ignorance is a reason people still believe that killing or having sexual intercourse with a child will bring a fortune. Again, ignorance is a reason people still hold harmful cultural practices and beliefs. Moreover, it is because people are poor that they facilitate child trafficking for domestic work and prostitution. Some parents, as mentioned above, allow these children to drop out of school so as to get married. It is also because of poverty that parents do not report sexual abuse incidences. Families are prepared to protect a perpetrator who is a family member, particularly if he is breadwinner, or to maintain a family relationship at the child victim's expense. Further, when a perpetrator is not a family member or a breadwinner parents do allow for an out-of-court settlement where they are paid "compensation." Poverty may be regarded as a cause and effect of child sexual abuse. Policies on poverty reduction, thus, should take a holistic approach, particularly in developing countries.

In many developing countries poverty, harmful cultural practices and child abuse are addressed in isolation. For instance, poverty reduction policies largely focus on improving standard of living and are informed by the sustainable development goals. On the other hand, harmful cultural practices and child protection are largely connected with promoting and protecting human rights and are largely informed by human rights standards. However, the fact that poverty is a cause and effect of child sexual abuse makes it imperative that a holistic approach is adopted in formulating and implementing poverty-reduction policies.

\section{Conclusion}

In conclusion, it has been shown in this paper that customs and traditions influence the perception of the way children (particularly girls) are treated. Child victims are blamed instead of being supported. In an African context a girl wearing a mini-skirt deserves to be raped. All, of this is justified in the name of customs and tradition. Sexual intercourse with children so as to become rich is also deeply rooted in superstition which is also informed by customs that human rights instruments categorise as "harmful practices." However, a close scrutiny of the causes of child sexual abuse and harmful practices suggests that they are largely associated with poverty. Therefore, to adequately protect children, developing countries need evidence-based policies. For 
instance, policies on poverty reduction should be informed by evidence and should be formulated and implemented within a broad scope of protecting children from sexual abuse as well as eliminating harmful cultural practices. This is a holistic approach that developing countries may use to achieve both child protection and poverty reduction.

Protection of children from sexual abuse is a global concern that calls for further research. In addition, an holistic approach may be employed to investigate child abuse further, particularly in developing countries where customs and tradition as well as child abuse are embedded in poverty as a cause and effect. For instance, the perpetration of child sexual abuse because of a belief that one will become rich needs to be investigated further. Child sexual abuse may also be examined as part of an assessment on measures that states parties to the CRC and/or the African Children's Charter have taken to protect children from all forms of violence and to eliminate harmful cultural practices. In addition, although measures taken in Tanzania may not be considered adequate, developing countries may still draw some lessons from Tanzania in respect of policy and other measures as well as legal reforms.

\section{References}

\section{International and regional instruments}

African Union. African Charter on the Rights and Welfare of the Child, OAU Doc. CAB/LEG/24.9/49.1990). Entered into force 1999 November 29.

United Nations. Convention on the Rights of the Child.1989. G.A. Res. 44/25, annex, 44 U.N. GAOR Supp. (No. 49) at 167, U.N. Doc. A/44/49 (1989), entered into force 1990 September 2.

United Nations. Protocol to Prevent, Suppress and Punish Trafficking in Persons, Especially Women and Children. 2000. Supplementing the United Nations Convention Against Transnational Organized Crime, G.A. Res. 25, annex II, U.N. GAOR, 55th Sess., Supp. No. 49, at 60, U.N. Doc. A/55/49 (Vol. I) (2001), entered into force 2003 December 25.

\section{Tanzanian legislation}

TANZANIA. Anti-Trafficking in Persons Act. 6 of 2008.

TANZANIA. The Law of the Child Act. 21 of 2009.

TANZANIA. The Penal Code. Chapter 16 of the Laws of Tanzania.

Articles, monographs, reports, etc.

Badoe, E., 2017. A critical review of child sexual abuse and its management in Africa. African Journal of Emergency Medicine. 7 (Suppl.), 32-35.

Bakta, S. 2018. Proceedings of a child victim of sexual offence: questioning the compatibility of Tanzanian laws with international standards. The Tanzania Lawyer.1 (2), 39-74.

Banwari, M. 2011. Poverty, child Sexual abuse and HIV in the Transkei Region, South Africa. African Health Sciences 11 (1), 117-121.

BBC News/Swahili. 2019. Father 'sold' a child to Tanzanian killers for $\$ 2,000$. Retrieved from https://www.bbc.com/swahili/habari-48252658 [2019, June 03].

Bizikova, L. 2011. Understanding the contribution of the environment to human well-being: A review of literature. Winnipeg, Canada: International Institute for Sustainable Development. Retrieved from https://www.iisd.org/pdf/2012/understanding_contribution_environment.pdf [2019, June, 17].

Bower, C. 2003. The relationship between child abuse and poverty. Agenda: Empowering Women for Gender Equity. 56, 84-87.

Brooks-Gunn, J. \& Duncan, G. J. 1997. The effects of poverty on children. The Future of Children. 7 (2), 55-71.

Citizen Reporter. 2019 (January 28). 10 Children brutally killed in suspected ritual murders. The Citizen, Retrieved from https://www.thecitizen.co.tz/news/10-children-brutally-killed-in-suspected-ritualmurders/1840340-4954892-lyoi8n/index.html. [2019 June 21]. 
Compassion International. 2019. Effects of poverty on children. Retrieved from https://www.compassion.com/poverty/effects-of-poverty-on-children.htm [2019 June 19].

Dubowitz, H., (2017) Child sexual abuse and exploitation: A global glimpse. Child abuse\& Neglect 66, 2-8.

Fourie, A.N .2015. Expounding the place of legal doctrinal methods in legal Interdisciplinary research. Erasmus Law Review.3. 95-109.

Haughton, J. \& Khandker,S. 2009, Handbook on poverty and inequality. Washington DC: World Bank.

Hillis, S. 2016. Global prevalence of past-year violence against children: a systematic review and minimum estimates. Pediatrics. 137 (3), 1-14.

Kamazima, S., Ezekiel M. \& Kazaura. M. 2016 Study report: dynamics of trafficking in persons in Tanzania. Dar es Salaam: International Organisation for Migration.

Kimati, B. 2017. TASAF money fails the poor. Guardian on Sunday, 8 January.

Kenny C. \& McEceny G. 2000. Racial, ethnic and cultural factors of childhood sexual abuse: A selected review of the literature. Clinical Psychology Review. 20 (7), 905-922.

Koyabashi, J., Becker, J.V., Sales, B. \& Figuerdo, A.J. 1995. Perceived parental deviance, parent-child bonding, child abuse, and child sexual aggression. A Journal of Research and Treatment. 7 (1), 25-44.

Lalor, K.2004a. Child sexual abuse in sub-Saharan Africa: a literature review. Child Abuse and Neglect 28 (4): $439-460$

Lalor, K 2004b. Child sexual abuse in Tanzania and Kenya. Child Abuse and Neglect. 28 (8), 833-844.

Legal and Human Rights Centre. 2018. Human rights report 2018. Retrieved from https://www.humanrights.or.tz/reports/tanzania-human-rights-report-2018 [2019, June 11].

Legal and Human Rights Centre. 2018. Human rights situation report January-June 2018. Retrieved from https://www.humanrights.or.tz/assets/attachments/1535740958.pdf[2019, June 13].

Legal and Human Rights Centre \& Zanzibar Legal Services Centre. 2016. Tanzania human rights report - 2016: mainland and Zanzibar. Retrieved from https://www.humanrights.or.tz/assets/attachments/1504340301.pdf [2019, June 11].

Murray L., Nguyen A. \& Cohen J., 2014. Child sexual abuse. Child Adolesc Psychiatr Clin N Am 23 (2) 321 337.

Narayan, D., Patel, R., Schaffte, K., Rademacher, A. \& Koch-Schulte, S. 2000. Voices of the poor: can anyone hear us? Oxford: Oxford University Press.

National Bureau of Statistics. 2016. Child poverty in Tanzania. Dar es Salaam: NBS.

Nkansah. L. A. \& Chibwanda, V. 2016. Interdisciplinary approach to legal scholarship: A blend from the qualitative paradigm. Asian Journal of Legal Education.3 (1) 55-71.

Pogge, T. 2003. UNESCO Poverty Project: ethical and human rights dimensions of poverty: towards a new paradigm in the fight against poverty [Philosophy seminar, All Soul's College]. Oxford: The College.

Ritcher. L., Dawes, A. \& Higson-Smith, C. Eds. 2004. Sexual abuse of young children in southern Africa. Cape Town: HSRC Press.

Roser, M. \& Ortiz-Ospina, E. 2017. Global extreme poverty. Retrieved from https://ourworldindata.org/extreme-poverty [2019, June 10].

Shafe, S. \& Hutchinson, G. 2014. Child sexual abuse and continuous influence of cultural practices: a review. Indian Med J. 63 (6), 634-637.

Taekema,S. \& Van der Burg, W. 2015. The incorporation problem in interdisciplinary legal research. Erasmus Law Review (2), 39-42.

Tanzania. 2010. National Strategy for Growth and Poverty Reduction (NSGRP II). Available: http://www.tzonline.org/pdf/mkukutalldraft.pdf [2019, May 16 ].

Tanzania. 2011. Violence against children in Tanzania: findings from a National Survey 2009. Dar es Salaam: [Government Printer].

$\begin{array}{lllll}\text { Tanzanian } & \text { Development } & \text { Vision } & 2025 . & \text { Retrieved }\end{array}$ http://www.tzonline.org/pdf/theTanzaniadevelopmentvision.pdf [2019, May 16]. 
UNICEF. Tanzania. 2016. Report on the study of drivers of violence against children and positive change in Mainland Tanzania and Zanzibar. [Not yet in the public domain].

United Nations. General Assembly. 2006. Report of the Independent Expert for [the] UN Study on Violence against Children, UN Resolution A/61/299. New York: UN.

United States of America. Department of State. 2018. Trafficking in persons report. Washington DC: The Department.

Ventura, L., 2019. Poorest countries in the world 2019. Global Finance, 17 April.

Yussuph, I., 2016. Tanzania: villagers hail TASAF poverty-reduction policy. Tanzania Daily News, 27 January.

Wangamati, $C$ et al., Sexualized violence against children: A review of laws and policies in Kenya. Sexual and Reproductive Health Matters 27 (1), 1-13.

World Bank. 2013. Tanzania mainland poverty assessment. Washington DC: The World Bank.

World Bank, 2019a. Poverty. The World Bank. Retrieved from https://www.worldbank.org/en/topic/poverty/overview [2019,June 11].

World Bank , 2019b. The World Bank in Tanzania. Dar es Salaam: The World Bank. Retrieved from https://www.worldbank.org/en/country/tanzania/overview [2019, June 30].

World Health Organisation. 2003. Guidelines for medico-legal care for victims of sexual violence. Geneva: WHO. 